\title{
A Novel Fractal Multi-band Frequency Selective Surface
}

\author{
Mahmoud Fallah $^{1}$ (D), Amir Hossein Nazeri*1,2 (D) , Mohammad Reza Azadkhah ${ }^{1}$ (D) \\ ${ }^{I}$ Department of Electrical Engineering, Iran University of Science \& Technology, Tehran, Iran, \\ m_falah@iust.ac.ir, *amirhossein20nazeri@gmail.com \\ ${ }^{2}$ School of Electrical and Computer Engineering, Texas Tech University, Texas, USA, \\ mohamdrezaazadkhah7480@gmail.com
}

\begin{abstract}
In this paper, a new multiband fractal frequency selective surface (MF-FSS) is proposed. The work presents a new fractal design methodology for FSSs with Swastika fractal patch elements. The proposed MF-FSS includes periodic arrays of metallic patches, printed on a single layer substrate. The structure parametric analysis is carried out in terms of fractal iterations, geometry elements, and unit-cell size. The simple controllable feature of the proposed structure lets us tune the given parameters of FSS geometry to achieve adjustable bandstop filter. The fractal geometry allows us to design compact structures $(\mathrm{CP}=54 \%)$ that behave like dual-polarized bandstop filters. The designed structure is validated by means of an excellent agreement between the simulation and measurement results. Also, results show the proposed structure presents the most desirable features like fractal compactness, multiband response, dual polarization, excellent angular stability, and controllability. This work presents a fundamental structure that can be applied into the more complex and sophisticated designs in future.
\end{abstract}

Index Terms - Frequency Selective Surface, Fractal, Angular Stability, Dual Polarization, Multi-band, Absorbers, Band Stop Filters, Home Shielding.

\section{INTRODUCTION}

Since the last decades, Frequency Selective Surfaces (FSSs) have received remarkable attention due to their widespread applications as electromagnetic filters for microwave and optical signals, like: radomes, dichroic sub-reflectors, bandpass, and bandstop filters, absorbers and artificial electromagnetic band-gap materials [1][3]. Nowadays, selective spatial filters are employed to establish indoor wireless security and to optimize Wireless Local Area Network (WLAN) coverage. For instance, FSSs may be applied, into the walls and windows of a building to modify the physical indoor propagation environment, isolating or avoiding interference among WLAN radios [4], [5]. Researchers have proposed different types of FSS configurations in the development of high performance spatial filters, such as: single-layer FSS with different elements in a periodic cell, [6] stacked or multilayered FSS structures, [7], [8] periodic arrays on anisotropic substrates [9]. Gomes, Mamedes et al in [10], have proposed a new reconfigurable four-arms star Frequency Selective Surface by embedding PIN diode in appropriate way. Recently, some analytical methods have been proposed to achieve fast and accurate structures. In [11], [12], new analytical approaches are presented based on equivalent circuits of Square and Hexagonal patches. A new approach is introduced to design FSS structures based on tuning the 
frequency response of each layer, [13], [14]. But, one of the most attractive and desirable features of FSS structures is operating band controllability. In this case, engineers are able to receive their desirable operating bands by changing some determined and specific elements of the FSS structure. Thus, no extra new experiment is required whenever a new band is needed. One way to achieve this feature can be the use fractal structures. Fractal structures due to their enhancement features have been employed for many of the applications in microwave filters [15], microstrip antennas [16] and frequency selective surfaces [17]. In following several examples of FSSs using periodic arrays of fractal resonant elements have been reported. In [18], a Frequency selective surfaces (FSSs) with fractal four-legged aperture elements are presented by Zhang et al, and three different order fractal elements are discussed for comparison. Ray et al [19], proposed a fractal FSS suitable for WLAN and WiMAX communications. Three fractal FSSs namely Sierpinski Carpet, Koch Snowflake, and Sierpinski Gasket have been investigated. An angularly stable FSS with hexagonal fractal configurations is presented in [20]. Different substrates are used and the operating possible applications for WiMAX, WLAN and cellular communication are investigated. Silva et al, in [21] produced a new fractal FSS based on Jerusalem Cross unit-cells. By adding new dipoles for each iteration new resonant frequencies have appeared. In [31], A Swastika geometry is utilized as the FSS unit-cell. The structure is not fractal. Not only is the structure multilayer also is single band.

In this paper, a novel multi-band fractal frequency selective surface (MF-FSS) is proposed. The structure is composed of Swastika geometry unit-cells and the three first iterations of MF-FSS structure is investigated. It is shown that by increasing the order of fractal iterations new resonant frequencies appear. Also, controllability is the significant feature of this structure. By tuning some specific parameters of the proposed structure's elements, which are totally investigated in the experiment, widespread desired resonant frequencies are accessible, easily. In addition, the angular stability of the frequency response with respect to polarization and incident angles is studied. The results show a perfect angular stability for this structure. At last, a prototype of the proposed MFFSS is fabricated and measured. The simulation and measurement results agree with a good level of accuracy, which demonstrates the excellence in structure performance.

\section{DESIGN PROCESS}

In this section we start by introducing a new fractal geometry to be employed in FSS structure unitcell. The base geometry of the proposed MF-FSS is a Swastika-like patch. In continuous, experiments with two next iterations of base geometry is carried out, as well. The Proposed MF-FSS is printed on a Rogers RO4003 substrate with dielectric constant $\varepsilon_{r}=3.55$, thickness $h=0.5 \mathrm{~mm}$, and loss tangent $\delta=0.0027$. Figure 1 shows the shapes presented by Swastika fractal patches with periodicity $p=13 \mathrm{~mm}$. The generation of the proposed fractal starts from one Swastika patch of sides $K=4.5 \mathrm{~mm}, K l=2.5$ and $w=0.2 \mathrm{~mm}$, that corresponds to the fractal initiator element ( $1^{\text {st }}$ iteration). The $K, K l$ and $w$ are the tuning parameters in each iteration, where $w$ is the thickness of each strip line of Swastika patches. The physical parameters of each iteration are listed in Table I. 


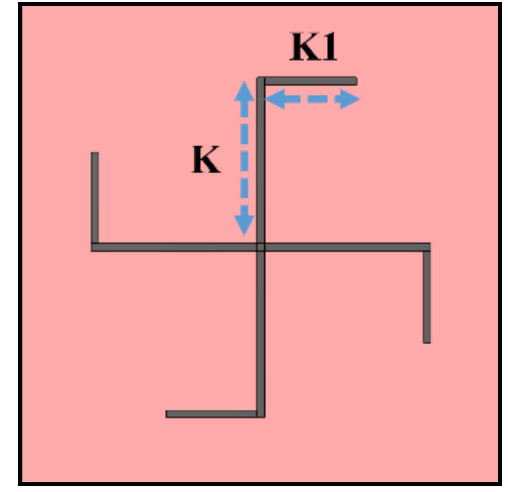

(a)

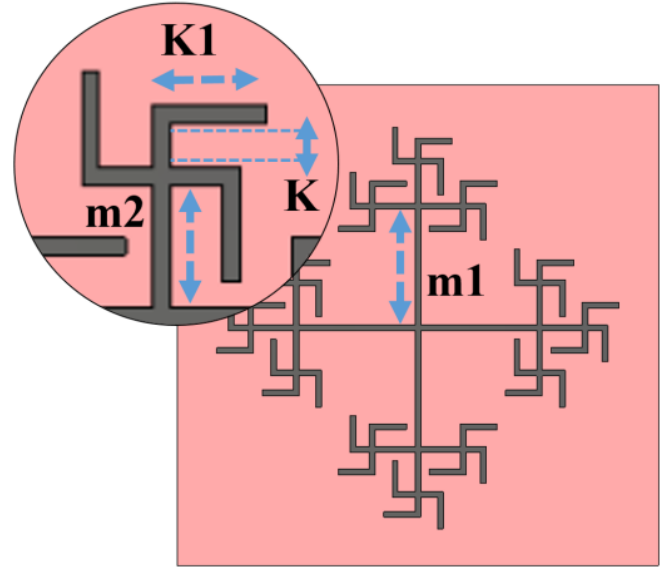

(c)

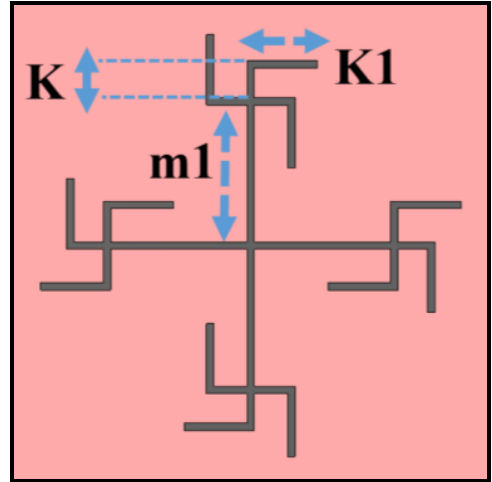

(b)

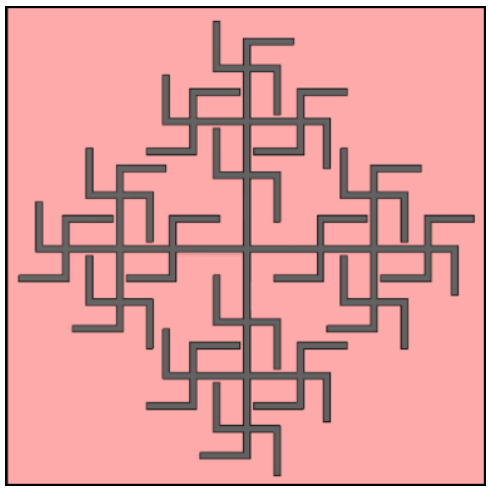

(d)

Fig 1. The sketch of proposed MF-FSS structure composed of Swastika fractal unit-cells. (a) The first iteration of structure, (b) the second iteration, (c) third iteration (d) the Modified-third iteration.

\section{RESULTS AND DISCUSSION}

In Fig. 2, the simulation results of all iterations are shown. The TE incident wave is considered for simulations.

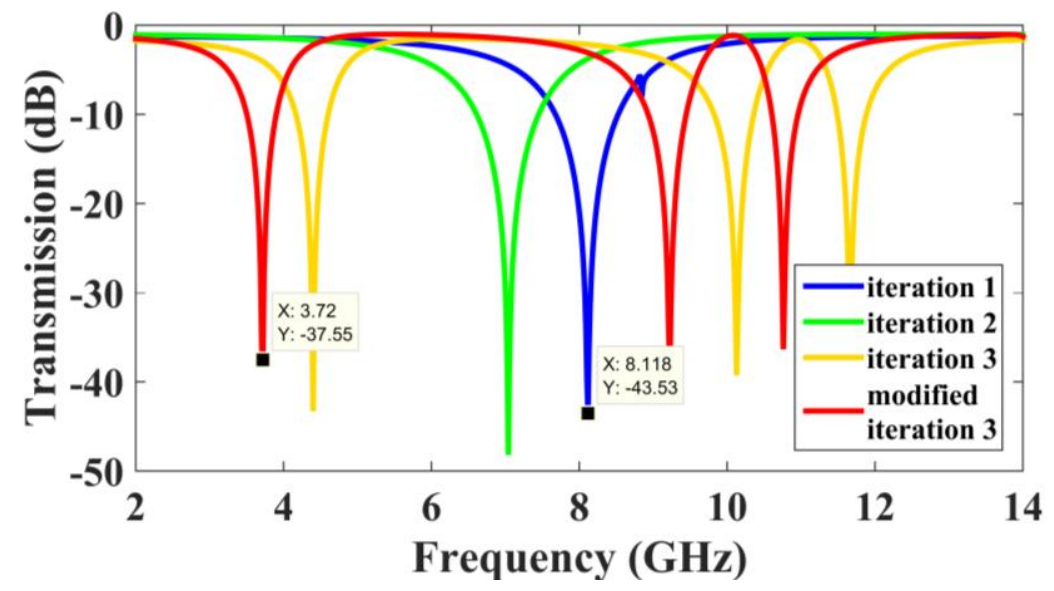

Fig 2. The transmission coefficients for MF-FSS iterations 1, 2, 3 and 3-modified. 
TABLE I. PHYSICAL PARAMETERS OF FSS ITERATIONS

\begin{tabular}{|c|c|c|c|c|c|c|}
\hline \multirow{2}{*}{ Iterations } & \multicolumn{6}{|c|}{ Parameters (mm) } \\
\hline & $K$ & $K 1$ & M1 & M2 & $W$ & $P$ \\
\hline First level & 4.5 & 2.5 & - & - & 0.2 & 13 \\
\hline Second level & 0.8 & 1.6 & 3.9 & - & 0.2 & 13 \\
\hline Third level & 0.9 & 1.8 & 4.2 & 1.9 & 0.2 & 13 \\
\hline
\end{tabular}

According to Fig. 2, by increasing the level of fractal iterations, the resonant frequencies are decreased and the number of them is increased. As expected, improved results are obtained for the higher level of iterations (third iteration). The third iteration presents a multi-band performance due to space-filling and self-similarity fractal properties. In addition, comparing the simulated results of first resonance for $1^{\text {st }}$ iteration $(3.72 \mathrm{GHz})$ and $3^{\text {rd }}$ iteration $(8.12 \mathrm{GHz})$, high frequency compactness factor $(\mathrm{CF}=54 \%)$ obtained. Moreover, based on symmetrical shape of structure and results of Fig. 2, the dual- polarization performance (TE, TM) is obtainable for this structure.

In the following, the effects of fundamental parameters of MF-FSS on structure performance is investigated. The significant parameter that has the most impact is unit-cell size. Obviously, the resonant frequencies reduce by increasing the size of unit-cell. In Fig. 3, the effect of this parameter on the first iteration is shown.

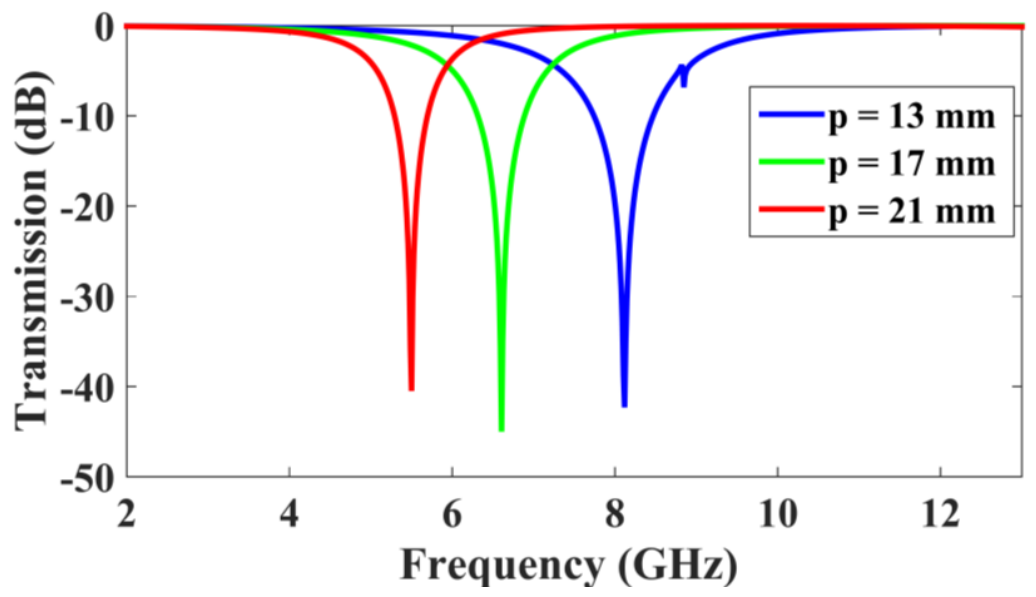

Fig 3. The S21 results of first iteration structure in terms of unit-cells size.

Figure 4 demonstrates the effect of tuning $K$ parameter on performance of modified $3^{\text {rd }}$ iteration. $K$ value is tuned from 0.7 to $1.1 \mathrm{~mm}$. the other parameters of the structure is same in each experiment. $K 1=1.6 \mathrm{~mm}, w=0.2 \mathrm{~mm}, M 1=4.2 \mathrm{~mm}, M 2=1.8$ and $p=13 \mathrm{~mm}$. As it is observable, the increase of $K$ decreases the resonant frequencies. The notable point is that by changing $K$ to $1.1 \mathrm{~mm}$ the number of Brazilian Microwave and Optoelectronics Society-SBMO received 30 Nov 2018; for review 6 Dec 2018; accepted 29 Apr 2019 Brazilian Society of Electromagnetism-SBMag 
resonant frequencies increased. Normally, FSS performance is affected by width of patch $(w)$ in unitcells (width of Swastika's strip lines in Fig 1). Physically, FSS unit cells under the plane wave propagation can be modeled by an equivalent resonance circuit with the resonant frequency $f=1 / 2 \pi \sqrt{L C}$, where $L$ and $C$ are equivalent inductance and capacitance of the unit cell. It is clear that a narrower slot causes a larger equivalent capacitance, [22]. This is how the bandwidth changes by changing the geometry width $(W)$. To examine the effect of $\mathrm{W}$ on frequency response of the first iteration, a MF-FSS with $\mathrm{p}=13 \mathrm{~mm}, \mathrm{~K}=0.7 \mathrm{~mm}, K 1=1.6 \mathrm{~mm}, M 1=4.2 \mathrm{~mm}$ and $M 2=1.8$ is considered. $W$ parameter varies from $0.1 \mathrm{~mm}$ to $0.2 \mathrm{~mm}$ in Fig. 5 . We observe that when $W$ increases, the two first resonance frequencies remain unchanged, whereas the third one increases. To tune the second and third resonant frequencies simultaneously, we can change $K 1$ easily. For this purpose, four experiments are conducted in which all the parameters are identical, except for $K 1$ that varies from 1.2 to $1.8 \mathrm{~mm}$. the results are depicted in Fig. 6 .

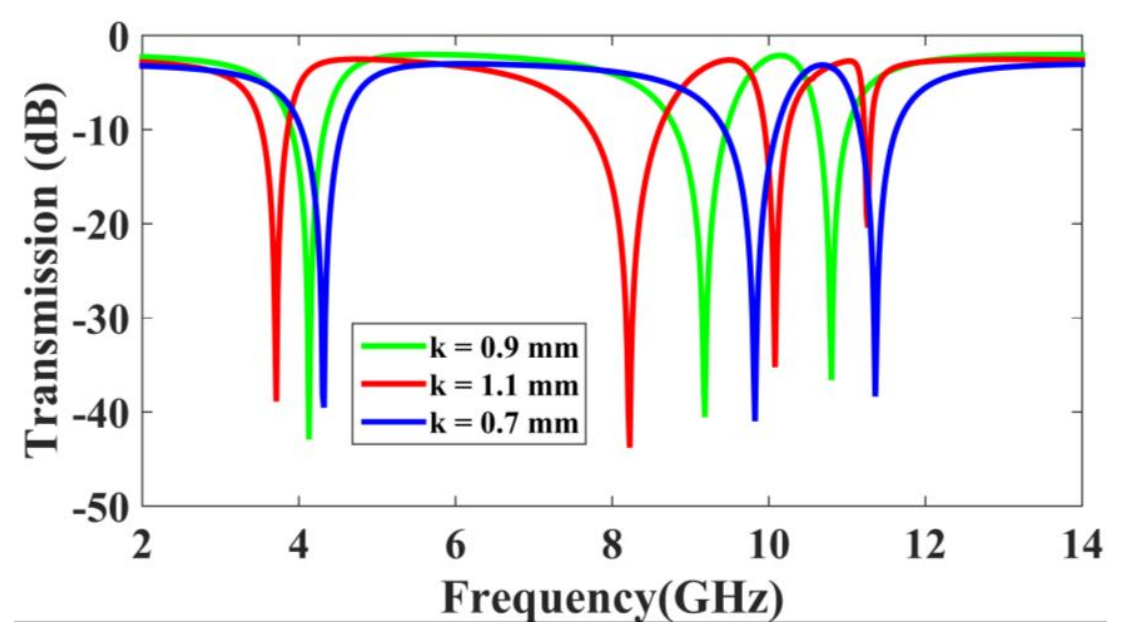

Fig 4. Transmission results of third iteration, for structures with different $\mathrm{k}$ parameters.

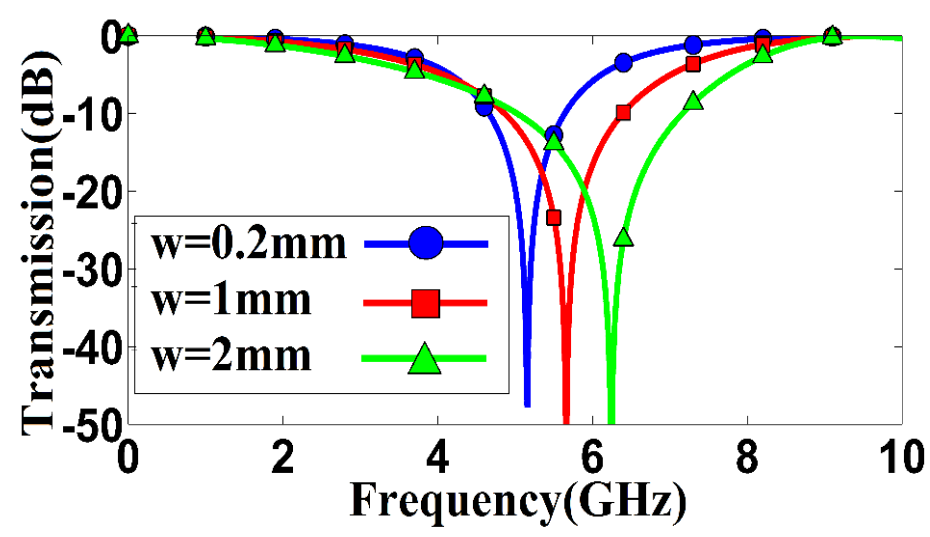

Fig 5. Transmission coefficient of the first iteration with different $w$. 


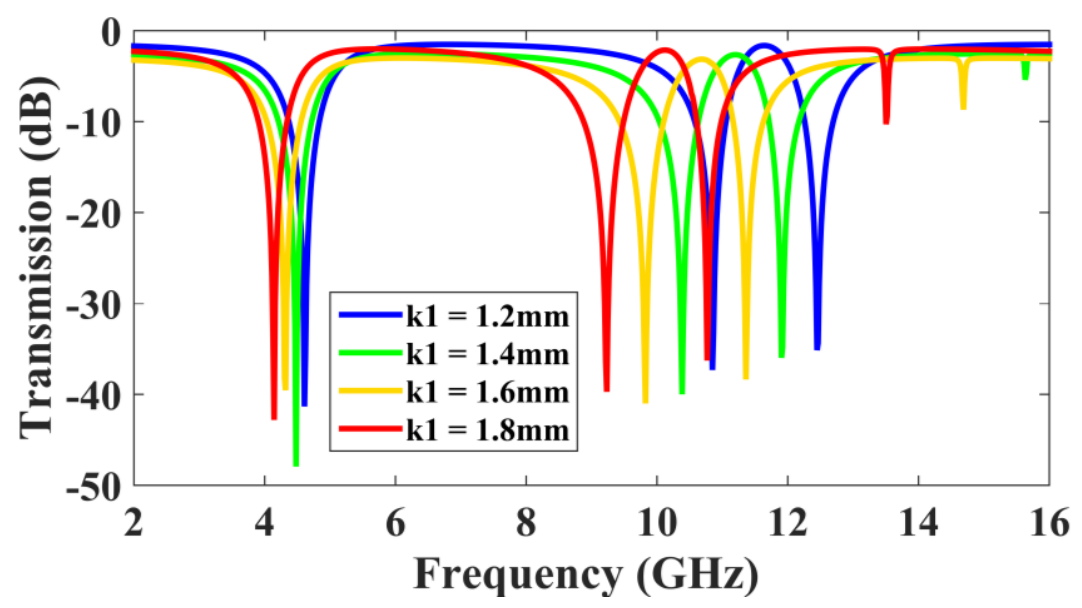

Fig 6. The simulation results of last iteration in terms of $K 1$

According to Fig. 6, by increasing the value of $K 1$ the resonant frequencies decrease. In this case we conceive that both $K$ and $K 1$ parameters have a significant effect on filter performance. But the critical point is that, according to Fig. 1, there is a trade-off between the values of $K$ and $K l$, when the unit-cell size is constant. Thus, we should find the optimized values for $K$ and $K l$ to achieve the best results. For this purpose, the experiment is repeated for the case that $K+K l$ has a constant value. The results of optimization is shown in Fig. 7. As Fig. 7 demonstrates, there is not much change in MFFSS simulation results that indicates, the proposed structure has the same sensitivity in respect of both parameters.

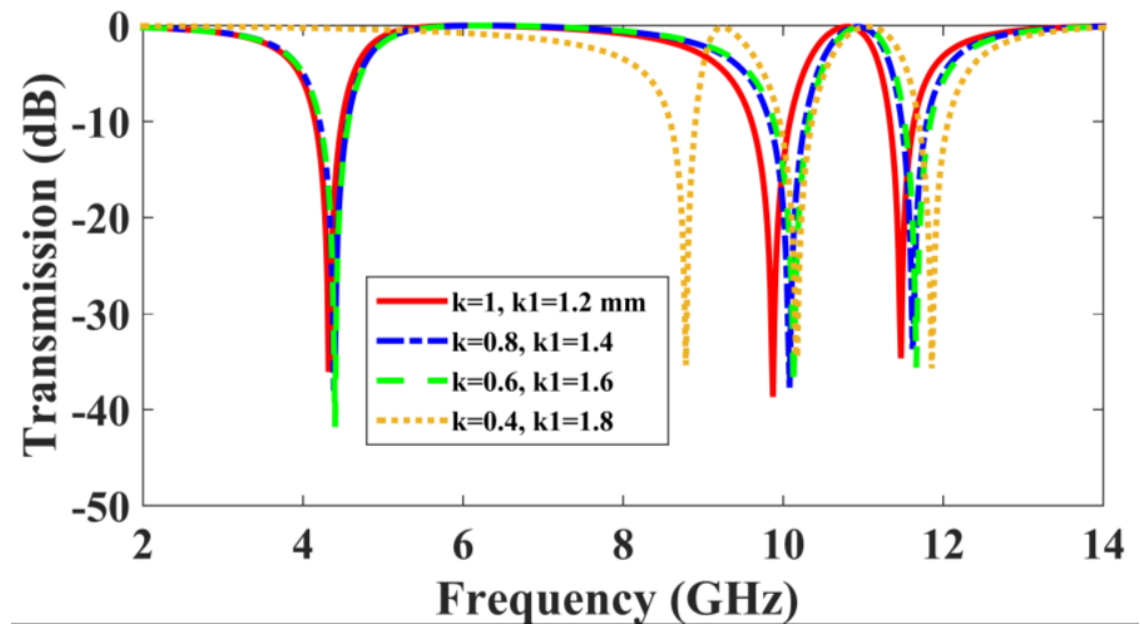

Fig 7. The $\mathrm{S} 21$ simulation results for last iteration when $K+K 1=2.2 \mathrm{~mm}$.

Due to the symmetrical configuration and space filling ability of the fractal, the proposed MF-FSS presents a good frequency stability for both TE and TM polarizations at different oblique angles. To verify the resonance stability of the FSS, simulation with different incident angles of the plane wave propagation on MF-FSS in last iteration is carried out. Fig. 8 shows the simulated results which confirm the great stability for different incident angles. 


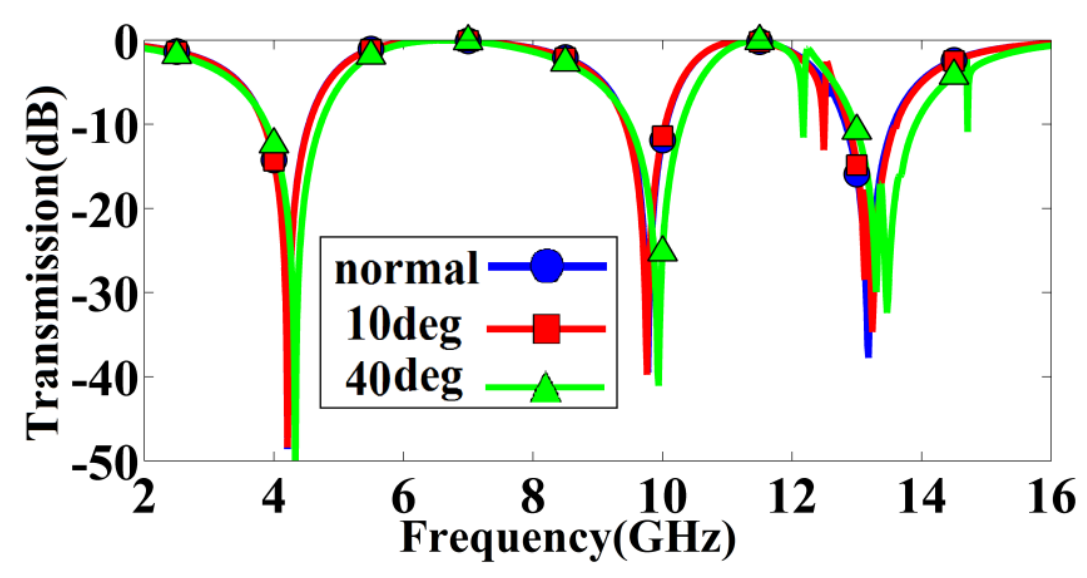

Fig 8. Transmission of the proposed MF-FSS under different incident angles

The proposed structure with the geometrical configuration presented in Fig. 1 (d) has been realized and its performance is investigated by HFSS 2017 software and measured in a standard anechoic chamber. This structure is fabricated on a Rogers RO4003 substrate with $0.508 \mathrm{~mm}$ thickness whose permittivity is 3.55 and its loss tangent is 0.0027 . The parameters of $3^{\text {rd }}$ iteration structure are: $K I=$ $1.6 \mathrm{~mm}, K=0.6 \mathrm{~mm}, W=0.2 \mathrm{~mm}, M 1=4.2 \mathrm{~mm}, M 2=1.8$ and $p=14 \mathrm{~mm}$. The simulated and measured results are presented in Fig. 9. Also, the prototype of the fabricated structure is shown, which comprises $14 \times 14$ unit cells and its dimension is $200 \mathrm{~mm} \times 200 \mathrm{~mm}$. According to Fig. 9, the measurement shows a good agreement with simulation results. In Table II, a comparison between this structure and recent similar works is made.

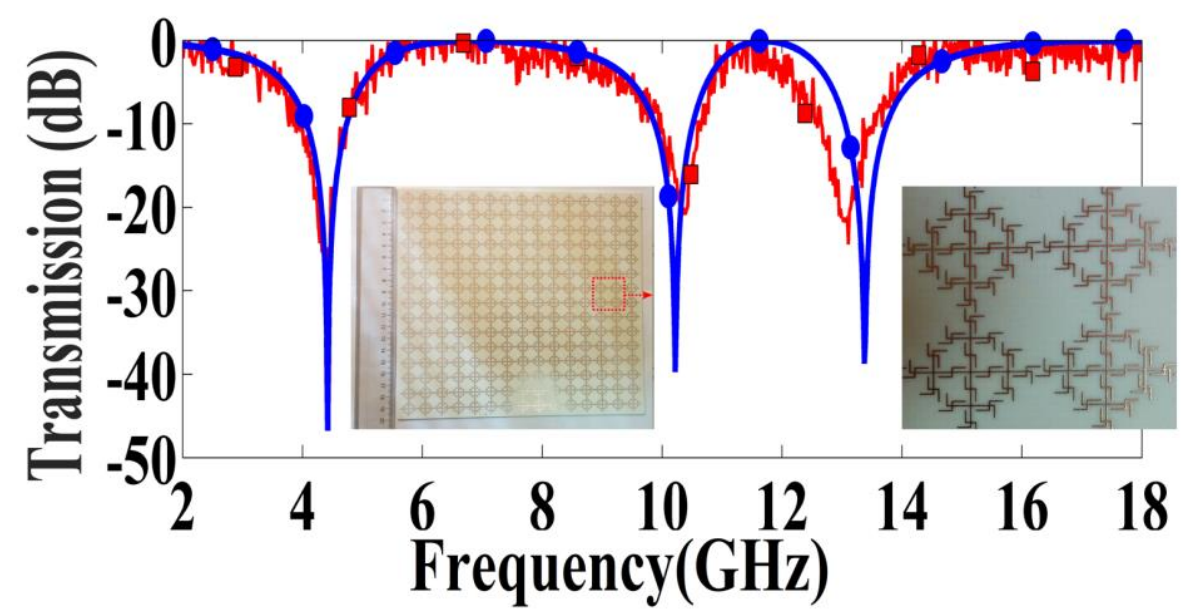

Fig 9. Comparison between measured and simulated results for the Modified third iteration structure, and a Photograph of the fabricated structure. 
TABLE II. COMPARISON BETWEEN THE SIMILAR WORKS AND THE PROPOSED STRUCTURE

\begin{tabular}{|c|c|c|c|c|c|c|}
\hline Reference & $\begin{array}{c}\text { Fractal } \\
\text { type }\end{array}$ & $\begin{array}{c}\text { Resonant } \\
\text { Freq. (GHz) }\end{array}$ & $\begin{array}{l}\text { Frequency } \\
\text { bands }\end{array}$ & $\begin{array}{c}\text { Unit-cell size } \\
\quad(\mathbf{m m})\end{array}$ & СР \% & $\begin{array}{c}\text { Dual- } \\
\text { polarized }\end{array}$ \\
\hline [23] & Yes & 8 & Single band & $\begin{array}{c}12.3 \\
0.328 \lambda\end{array}$ & 50.1 & Yes \\
\hline [24] & Yes & $8.03 / 6.45$ & Dual-band & $\begin{array}{c}16.5 \\
0.355 \lambda\end{array}$ & 43.52 & No \\
\hline [28] & Yes & $4.56 / 10.5$ & Dual band & $\begin{array}{c}16 \\
0.243 \lambda\end{array}$ & 66 & Yes \\
\hline [25] & Yes & $8.237 / 11.2$ & Dual-band & $\begin{array}{c}22 \\
0.57 \lambda\end{array}$ & 23.82 & No \\
\hline [26] & No & $6 / 8.25$ & Dual-band & $\begin{array}{c}20 \\
0.4 \lambda\end{array}$ & - & No \\
\hline [27] & Yes & 5 & Single band & $\begin{array}{c}15 \\
0.25 \lambda\end{array}$ & 47 & Yes \\
\hline [29] & No & 5.12 & Single band & $0.095 \lambda$ & 68 & Yes \\
\hline [30] & No & - & Single band & 10 & - & - \\
\hline [32] & No & 5 & Single band & $\begin{array}{c}7 \\
0.12 \lambda\end{array}$ & - & Yes \\
\hline $\begin{array}{l}\text { Proposed } \\
\text { MF-FSS }\end{array}$ & Yes & $\begin{array}{c}4.2 / 10.1 / \\
13.3\end{array}$ & Triple band & $\begin{array}{c}14 \\
0.19 \lambda\end{array}$ & 54 & Yes \\
\hline
\end{tabular}

\section{CONCLUSION}

In this paper, we presented a novel fractal geometry to design fractal FSS structures. The electromagnetic scattering properties of MF-FSSs designed with Swastika fractal patch elements is carried out at different fractal iterations. The Swastika fractal geometry provides desired FSS features, such as adjustability of resonant frequencies and bandwidth; higher miniaturization; stable filter responses at the oblique incidence of wave propagation. Also, the symmetry of patch elements geometry leads to dual polarization property (for both TE and TM waves). Moreover, by tuning the geometry elements controllability feature for adjusting resonant frequencies and bandwidth is accessible. For the fabricated prototype, there is a good agreement between the theoretical and experimental results.

\section{REFERENCES}

[1] Te-Kao Wu, Frequency selective surface and grid array, vol. 40. Wiley-Interscience, 1995.

[2] J. C. Vardaxoglou, Frequency selective surfaces: analysis and design, vol. 997, London: Research Studies Press, 1997.

[3] B. A. Munk, Frequency selective surfaces: theory and design, John Wiley \& Sons, 2005.

[4] M. Raspopoulos and S. Stavrou, "Frequency Selective Buildings Through Frequency Selective Surfaces," IEEE Transactions on Antennas and Propagation, vol. 59, no. 8, pp. 2998-3005, 2011.

[5] G. Kiani, L. Olsson, A. Karlsson, K. Esselle and M. Nilsson, "Cross-Dipole Bandpass Frequency Selective Surface for Energy-Saving Glass Used in Buildings," IEEE Transactions on Antennas and Propagation, vol. 59, no. 2, pp. 520-525, Brazilian Microwave and Optoelectronics Society-SBMO received 30 Nov 2018; for review 6 Dec 2018; accepted 29 Apr 2019 Brazilian Society of Electromagnetism-SBMag (C) 2019 SBMO/SBMag (cc) BY 

DOI: http://dx.doi.org/10.1590/2179-10742019v18i21559

2011.

[6] Mingyun, Lü, Huang Minjie, and Wu Zhe. "Design of multi-band frequency selective surfaces using multi-periodicity combined elements," Journal of Systems Engineering and Electronics, vol. 20, no. 4, pp. 675-680, 2009.

[7] L. Araújo, R. Maniçoba, A. Campos and A. D'Assunção, "A simple dual-band frequency selective surface," Microwave and Optical Technology Letters, vol. 51, no. 4, pp. 942-944, 2009.

[8] A. Qing and C. Lee, "An Improved Model for Full Wave Analysis of Multilayered Frequency Selective Surface with Gridded Square Element - Abstract," Journal of Electromagnetic Waves and Applications, vol. 14, no. 10, pp. 1397-1398, 2000 .

[9] A. Campos and A. D'Assunção, "Frequency selective surfaces on ISO/anisotropic substrates with dielectric losses," Microwave and Optical Technology Letters, vol. 49, no. 5, pp. 1041-1044, 2007.

[10] D. Mamedes, A. Gomes Neto, J. e Silva and J. Bornemann, "Design of reconfigurable frequency-selective surfaces including the PIN diode threshold region," IET Microwaves, Antennas \& Propagation, vol. 12, no. 9, pp. 1483-1486, 2018.

[11] M. Fallah, A. Ghayekhloo and A. Abdolali, "Design of Frequency Selective Band Stop Shield Using Analytical Method," Journal of Microwaves, Optoelectronics and Electromagnetic Applications, vol. 14, no. 2, pp. 217-228, 2015.

[12] M. Fallah and M. Hashem Vadjed-Samiei, "Designing a Bandpass Frequency Selective Surface Based on an Analytical Approach Using Hexagonal Patch-Strip Unit Cell," Electromagnetics, vol. 35, no. 1, pp. 25-39, 2014.

[13] E. Zanganeh, M. Fallah, A. Abdolali and N. Komjani, "New approach to design dual-band frequency selective surface based on frequency response tunning of each individual layer," Microwave and Optical Technology Letters, vol. 58, no. 6, pp. 1423-1429, 2016.

[14] H. Nasrollahi, et al. "Novel algorithm for designing reflect-array antennas based on analytical methods," AEU-International Journal of Electronics and Communications, vol.97, pp. 280-289, 2018.

[15] S. Karthie, and S. Salivahanan, "Hilbert fractal stub-based wideband microstrip bandpass filter with notched band on low-cost substrate," Microwave and Optical Technology Letters, vol. 60, no.5, pp. 1112-1115, 2018.

[16] A. H. Nazeri, A. Falahati, and R. M. Edwards, "A Novel Compact Fractal UWB Antenna with Triple Reconfigurable Notch Reject Bands Applications," AEU-International Journal of Electronics and Communications, vol. 101, pp. 1-8, 2019.

[17] R. Anwar, L. Mao, and H. Ning, "Frequency Selective Surfaces: A Review," Applied Sciences, vol.8, no. 9, pp. $1689,2018$.

[18] J. Zhang, Y. Yin and J. Ma, "Frequency selective Surfaces with Fractal four Legged Elements," Progress In Electromagnetics Research Letters, vol. 8, pp. 1-8, 2009.

[19] A. Ray, M. Kahar, D. Sarkar and P. Sarkar, "On fractal FSS suitable for WLAN and WiMAX communication", Microwave and Optical Technology Letters, vol. 57, no. 7, pp. 1546-1550, 2015.

[20] W. Wang, P. Zhang, S. Gong, B. Lu, J. Ling and T. Wan, "Compact angularly stable frequency selective surface using hexagonal fractal configurations", Microwave and Optical Technology Letters, vol. 51, no. 11, pp. 2541-2544, 2009.

[21] H. Silva Filho, C. Silva, M. Oliveira, E. Oliveira, M. Melo, T. Sousa and A. Gomes Neto, "Multiband FSS with Fractal Characteristic Based on Jerusalem Cross Geometry", Journal of Microwaves, Optoelectronics and Electromagnetic Applications, vol. 16, no. 4, pp. 932-941, 2017.

[22] B. A. Munk, Frequency selective surfaces: theory and design. John Wiley \& Sons, 2005.

[23] M. da Silva, C. Nóbrega, P. Silva and A. D'Assunção, "Dual-polarized band-stop FSS spatial filters using vicsek fractal geometry," Microwave and Optical Technology Letters, vol. 55, no. 1, pp. 31-34, 2012.

[24] J. Trindade, P. da F. Silva, A. Campos and A. D'Assuncao, "Analysis of Stop-Band Frequency Selective Surfaces With Dürer's Pentagon Pre-Fractals Patch Elements," IEEE Transactions on Magnetics, vol. 47, no. 5, pp. 1518-1521, 2011.

[25] P. Silva, A. dos Santos, R. Cruz and A. D'Assunção, "Dual-band bandstop frequency selective surfaces with gosper prefractal elements," Microwave and Optical Technology Letters, vol. 54, no. 3, pp. 771-775, 2012

[26] R. Saidi, M. Titaouine, A. Djouimaa, T. Sousa, A. Gomes Neto, K. Bencherif and H. Baudrand, "Characterization of Switchable Rectangular Ring FSS with Non Coupled Parallel Metallic Strips for Multi Band and Dual Polarized Applications Using WCIP Method," Journal of Microwaves, Optoelectronics and Electromagnetic Applications, vol. 17, no. 1, pp. 102-120, 2018.

[27] S. Zheng, Y. Yin, J. Fan, X. Yang, B. Li and W. Liu, "Analysis of Miniature Frequency Selective Surfaces Based on Fractal Antenna-Filter-Antenna Arrays," IEEE Antennas and Wireless Propagation Letters, vol. 11, pp. 240-243, 2012.

[28] C. L. Nóbrega, M. R. da Silva, P. F. Silva and A. D’Assunção, "A compact frequency selective surface with angular stability based on the Sierpinski fractal geometry," Journal of Electromagnetic Waves and Applications, vol. 27, no. 18, pp. 2308-

Brazilian Microwave and Optoelectronics Society-SBMO Brazilian Society of Electromagnetism-SBMag received 30 Nov 2018; for review 6 Dec 2018; accepted 29 Apr 2019 $\begin{array}{lll}\text { C } 2019 \text { SBMO/SBMag (cc) BY } & \text { BS } 2179-1074\end{array}$ 

DOI: http://dx.doi.org/10.1590/2179-10742019v18i21559

2316, 2013.

[29] S. Bilvam et al. "Miniaturized Band Stop FSS Using Convoluted Swastika Structure," Frequenz 71.1-2, pp. 51-56, 2017.

[30] B. Sangeetha et al. "Design of airborne radome using Swastika-shaped metamaterial-element based FSS," 2016 IEEE Annual India Conference (INDICON) IEEE, 2016.

[31] S. Narayan, et al. "Novel Metamaterial-Element-Based FSS for Airborne Radome Applications," IEEE Transactions on Antennas and Propagation, vol. 66, no. 9, pp. 4695-4707, 2018.

[32] R. Natarajan et al. "A compact frequency selective surface with stable response for WLAN applications," IEEE Antennas and Wireless Propagation Letters, vol. 12, pp. 718-720, 2013. 